\title{
Efektifitas Mirror Therapy terhadap Kekuatan Otot dan Status Fungsional Pasien Stroke Non Hemoragik
}

\author{
Istianah $^{1}$, I Gde Arsana ${ }^{2}$ Wiyantara, Hapipah ${ }^{3}$, Zaenal Arifin ${ }^{4}$ \\ ${ }^{1,3,4}$ Stikes Yarsi Mataram Jurusan Ilmu Keperawatan, Jl. Lingkar Selatan, Pagutan, \\ Kec. Mataram, Kota Mataram, Nusa Tenggara Barat \\ ${ }^{2}$ RSUD Kota Mataram, Jl. Bung Karno No.3, Pagesangan Tim., Kec. Mataram, \\ Kota Mataram, Nusa Tenggara Barat \\ E-mail: istianah85mataram@gmail.com
}

$\begin{array}{ll}\text { Diterima } & : 8 \text { Oktober } 2020 \\ \text { Disetujui } & : \text { 27 November 2020 } \\ \text { Dipublikasikan } & : \text { 10 Desember 2020 }\end{array}$

\begin{abstract}
Abstrak
Latar Belakang dan Tujuan: Stroke merupakan gangguan fungsi otak yang dapat berdampak pada berbagai fungsi tubuh diantaranya defisit motorik berupa hemiparese. Mirror Therapy merupakan salah satu terapi untuk pasien stroke dengan melibatkan sistem mirror neuron. Tujuan penelitian untuk mengetahui efektifitas mirror therapy terhadap kekuatan otot dan status fungsional pasien stroke dengan hemiparese.

Metode: Desain penelitian ini menggunakan pra eksperiment dengan pendekatan One Group Pre Test and Post Test Design. Populasi penelitian ini adalah semua pasien stroke yang dirawat inap di RSUD Kota Mataram berjumlah 108 orang. Sampel penelitian adalah pasien stroke non hemoragik dengan hemiparese berjumlah 16 responden yang dipilih dengan tekhnik purposive sampling. Instrumen penelitian: lembar observasi kekuatan otot, barthel indeks, dan cermin. Data dianalisis dengan univariat dan bivariate.

Hasil: Hasil penelitian didapatkan rata-rata kekuatan otot sebelum intervensi adalah 2,69 dan setelah intervensi 3.63, sedangkan rata-rata status fungsional sebelum intervensi 42,5 dan setelah intervensi menjadi 72,5. Hasil analisis dengan uji willcoxon diperoleh nilai $p$ value untuk kekuatan otot $0,000<0,05$ dan status fungsional $0,001<0,05$.

Simpulan dan Implikasi: Mirror therapy berpengaruh terhadap peningkatan kekuatan otot dan status fungsional pasien stroke dengan hemiparese, sehingga tehnik mirror therapy dapat digunakan sebagai penatalaksanaan dan perawatan untuk meningkatkan kekuatan otot dan status fungsional pasien stroke.
\end{abstract}

Kata Kunci: Kekuatan otot; Mirror therapy; Status fungsional; Stroke

Sitasi: Istianah, Arsana I G, Hapipah \& Arifin Z. (2020). Efektifitas mirror therapy terhadap kekuatan otot dan status fungsional pasien stroke non hemoragik. The Indonesian Journal of Health Science. 12(2), $158-168$

Copyright: (C) 2020 Istianah et. al. This is an open-access article distributed under the terms of the Creative Commons Attribution-NonCommercial 4.0 International License, which permits unrestricted use, distribution, and reproduction in any medium, provided the original author and source are credited.

Diterbitkan Oleh: Universitas Muhammadiyah Jember

ISSN (Print): 2087-5053

ISSN (Online): 2476-9614 


\begin{abstract}
Background and Aim: Stroke is a brain function disorder that can impact various body functions, including motor deficits in the form of hemiparese. Mirror Therapy is a therapy for stroke patients that involve the mirror neuron system. The aim of the study was to determine the effectivity of mirror therapy on muscle strength and functional status of stroke patients with hemiparese.

Methods: This research design used a pre-experiment with the One Group Pre Test and Post Test Design approach. The population in this study was all stroke patients who were hospitalized at the Mataram City Hospital a total of 108 people. The sample was 16 non-hemorrhagic stroke patients with hemiparese who were selected by purposive sampling technique. The research instrument was a muscle strength observation sheet, a Barthel index and a mirror. Data were analyzed by univariate and bivariate.

Results: The results showed that the average muscle strength before intervention was 2.69 and after intervention was 3.63, while the mean functional status before intervention was 42.5 and after intervention was 72.5. The results of the analysis with the Willcoxon test showed that the p value for muscle strength was 0.000 $<0.05$ and the functional status was $0.001<0.05$.

Conclusion: Mirror therapy has an effect on increasing muscle strength and functional status of stroke patients with hemiparese, so that mirror therapy techniques can be used as a management and treatment to improve muscle strength and functional status of stroke patients.
\end{abstract}

Keywords: Functional status; Mirror therapy; Muscle strength; Stroke

\section{PENDAHULUAN}

Penyakit stroke merupakan salah satu masalah kesehatan yang menjadi penyebab utama kecacatan pada usia dewasa di dunia. Di negara berkembang, stroke menempati urutan ketiga sebagai penyebab utama kematian setelah penyakit jantung koroner dan kanker serta menyumbang $85.5 \%$ dari total kematian diseluruh dunia. Terdapat sekitar 13 juta kasus baru setiap tahun dengan jumlah kematian sekitar 4.4 juta pertahun (WHO, 2010). Sedangkan data Organisasi Kesehatan Dunia (WHO) tahun 2016 menunjukkan, stroke menempati peringkat kedua sebagai penyakit tidak menular yang menyebabkan kematian dan menjadi peringkat ketiga penyebab utama kecacatan diselurh dunia.

Menurut American Heart Assosiation (AHA) tahun 2015 angka kejadian stroke pada setiap usia berbeda-beda, dimana pada usia 40-59 tahun kejadian stroke pada laki-laki sebanyak $0,2 \%$ dan perempuan $0,7 \%$, sedangkan pada usia 60-79 tahun yang menderita stroke pada perempuan $5,2 \%$ dan laki-laki sekitar 6,1\%. Prevalensi stroke pada usia lanjut semakin meningkat dan bertambah setiap tahunnya, dimana pada usia 80 tahun keatas angka kejadian stroke pada 
laki-laki sebanyak $15.8 \%$ dan pada perempuan sebanyak $14 \%$.

Hasil Riskesdas tahun 2018 menunjukan, prevalensi stroke berdasarkan diagnosis pada penduduk berusia lebih dari 15 tahun adalah 10,85 persen. Angka kejadian stroke di kota Mataram cukup tinggi, hal tersebut dapat dilihat dari angka kunjungan pasien stroke di Rumah Sakit Umum Daerah Kota Mataram yang terus mengalami peningkatan setiap tahun. Tahun 2016 terdapat 228 pasien stroke yang terbagi menjadi 53 pasien dengan Stroke Non Hemoragik dan 175 pasien dengan Stroke Hemoragik, tahun 2017 jumlah pasien stroke 684 pasien, dengan 504 pasien Stroke Non Hemoragik dan 180 pasien Stroke Hemoragik (Rekam Medik RSUD Kota Mataram, 2018)

Stroke merupakan kelainan fungsi otak yang terjadi secara mendadak, disebabkan oleh terjadinya gangguan peredaran darah pada daerah otak yang dapat terjadi pada siapa saja dan kapan saja. Penanganan yang terlambat pada penderita stroke dapat menyebabkan kecacatan berupa kelumpuhan anggota gerak, gangguan bicara, proses berpikir, dan daya ingat sebagai dari akibat gangguan fungsi otak (Muttaqin, 2008). Pada pasien stroke $70-80 \%$ pasien mengalami hemiparesis (kelemahan otot pada salah satu sisi bagian tubuh) dengan $20 \%$ dapat mengalami peningkatan fungsi motorik dan sekitar 50\% mengalami gejala sisa berupa gangguan fungsi motorik/kelemahan otot pada anggota ekstrimitas bila tidak mendapatkan pilihan terapi yang baik dalam intervensi keperawatan maupun rehabilitasi pasca stroke (Feri, 2017).
Hemiparese merupakan penyebab yang sering terjadi setelah serangan stroke. Penanganan hemiparese ditujukan untuk meningkatkan fungsi motorik dan mencegah kontraktur, sehingga perlu penatalaksanaan yang tepat agar tidak terjadi gangguan fungsi motorik dan kerusakan kontraktur pada pasien stroke (Khairunnisa, 2014). Berbagai penatalaksanaan dapat dilakukan pada pasien stroke dengan kelemahan otot. Selain terapi medikasi atau obat-obatan,tindakan yang dapat dilakukan antara lain dengan fisioterapi/latihan seperti latihan beban, keseimbangan dan latihan ROM (Range Of Motion). Selain terapi rehabilitasi ROM yang sering dilakukan pada pasien stroke, terdapat alternatif terapi lainnya yang diterapkan pada pasien stroke untuk meningkatkan status fungsional pada sensori motorik, yaitu terapi latihan rentang gerak dengan menggunakan media cermin (mirror therapy).

Latihan mirror therapy adalah bentuk rehabilitasi latihan yang mengandalkan dan melatih pembayangan imajinasi motorik pasien dimana cermin akan memberikan stimulus visual kepada otak saraf motorik serebral yaitu ipsilateral atau kontralateral untuk pergerakan anggota tubuh yang hemiparese melalui observasi dari pergerakan tubuh yang akan cenderung ditiru seperti cermin oleh bagian tubuh yang mengalami gangguan (Herianto, 2015). Therapy mirror merupakan terapi untuk pasien stroke dengan melibatkan sistem mirror neuron yang terdapat di daerah kortek serebri yang bermanfaat dalam penyembuhan motorik dari tangan dan gerak mulut. Terapi ini bertujuan untuk memperbaiki status fungsional, 
mudah dilakukan dan hanya membutuhkan latihan yang singkat tanpa membebani pasien (Olivia, 2017).

Pada umumnya outcome stroke digambarkan dalam bentuk angka kematian dan status fungsional setelah serangan stroke (Khasanah, 2012). Penurunan kemampuan dapat terjadi dikarenakan penurunan kesadaran serta daerah otak tertentu tidak berfungsi yang disebabkan terganggunya aliran darah ditempat tersebut (Fandri et al, 2014).

Pasien stroke dengan hemiparese sering mengalami ketidakmampuan dalam gerakan terutama dalam pemenuhan kebutuhan sehari-harinya seperti makan, mandi, berdandan, mobilisasi dari tempat tidur ke kursi roda, berjalan di tempat yang datar, menaiki atau menuruni anak tangga, berpakaian,toileting, dan beraktivitas.

Ketidakmampuan ini dikarenakan penyakit stroke yang dialami dapat menyebabkan kelumpuhan motorik. Hal ini biasanya menyebabkan pasien stroke sulit untuk melakukan gerakan-gerakan tangan dan kaki di bagian otak yang terserang stroke sehingga pasien membutuhkan bantuann orang lain. Hal ini menunjukkan jika pasien terserang stroke, secara langsung dan dalam waktu serangan stroke terjadi, pasien akan mengalami ketidak berfungsian bagian otak tertentu sehingga akan mempengaruhi aktivitas gerak tubuh dan kehidupan sehari-hari. Oleh karena itu peneliti tertarik untuk melakukan penelitian tentang pengaruh tindakan mirror therapy untuk meningkatkan kekuatan otot dan status fungsional pasien stroke non hemoragik.

\section{METODE PENELITIAN}

Desain Penelitian ini menggunakan pra eksperimen dengan pendekatan One Group Pre Test and Post Test Design. Adapun populasi dalam penelitian ini adalah semua pasien stroke yang di rawat inap di RSUD Kota Mataram sebanyak 108 orang dan sampel yang diambil adalah pasien stroke non hemoragik dengan hemiparese sejumlah 16 orang. Tekhnik sampling menggunakan non probability sampling yaitu purposive sampling dan sampel dipilih berdasarkan kriteria inklusi yaitu: bersedia menjadi responden, tingkat kesadaran composmentis, tidak sedang menjalani program fisioterapi, mampu diajak berkomunikasi, tanda-tanda vital stabil dan memiliki kekuatan otot 2 . Etika dalam penelitian ini adalah Informed consent, Anonimity, Kerahasiaan (Confidentiality) dan Protection from Discomfort and Harm. Sebelum dilakukan pengambilan data dilakukan uji etik terlebih dahulu. Instrumen penelitian menggunakan quesioner, lembar observasi kekuatan otot, dan lembar observasi status fungsional (Barthel Indeks).

Intervensi mirror therapy, dilakuan 2 kali sehari, pagi dan sore selama 2 minggu selama 15 menit dan dikombinasikan dengan beberapa gerakan ROM. Setelah itu dilakukan pengukuran kekuatan otot dan status fungsional responden post intervensi.

Pengumpulan data dilakukan dengan mengukur kekuatan otot dan status fungsional pasien sebelum dan setelah dilakukan tindakan mirror therapy. Analisis data dalam penelitian ini menggunakan analisis univariat dan bivariate. Sebelum 
dilakukan uji statistik, peneliti melakukan uji normalitas data dengan menggunakan analisis Saphiro-Wilk dan karena data berskala interval tetapi berdistribusi tidak normal sehingga anaisis bivariat dengan uji statistik Wilcoxon Signed Rank Test.

\section{HASIL}

Hasil penelitian terdiri dari data umum (karakteristik responden) dan data khusus (variabel penelitian). Sampel dalam penelitian ini adalah pasien stroke non hemoragik dengan hemiparese yang dirawat di RSUD Kota Mataram dengan jumlah sampel 16 orang.

Tabel 1 menunjukkan rata-rata usia responden adalah 55,75 (56 tahun), sebagian besar dengan jenis kelamin laki-laki sebanyak 9 responden $(56,25 \%)$, kejadian stroke tertinggi adalah serangan pertama sebanyak 12 responden $(75 \%)$ dan keseluruhan responden (100\%) adalah penderita hipertensi dengan durasi lebih dari satu tahun.

Nilai rata-rata (mean) kekuatan otot sebelum diberikan intervensi mirror teraphy adalah 2,69 dengan median 3,00 standar deviasi 0,48 dan nilai kekuatan otot minimum 2 dan maksimum 3. Sedangkan rata-rata kekuatan otot setelah dilakukan mirror therapy adalah 3,63, dengan median 4,00, standar deviasi 0,62 dan nilai kekuatan otot minimum 2 dan maksimum 4. Status fungsional responden sebelum diberikan intervensi mirror teraphy didapatkan nilai rata-rata 42,50 atau kategori ketergantungan berat, dengan mean 50, standar deviasi 18,71 dan nilai minimum 10 atau kategori ketergantungan penuh dan maksimum 65 atau ketergantungan sedang. Sedangkan rata-rata (mean) untuk status fungsional responden setelah diberikan intervensi mirror teraphy adalah 72,50 atau ketergantungan sedang, dengan median 80, standar deviasi 21,45 dan nilai minimum 10 atau ketergantungan penuh dan maksimum 95 atau ketergantungan ringan (Tabel 2).

Tabel 3 menunjukkan bahwa jumlah negative ranks 0 artinya tidak ada responden yang kekuatan ototnya berkurang setelah diberikan mirror therapy, positif ranks 15 artinya ada 15 responden yang mengalami peningkatan kekuatan otot setelah diberikan mirror therapy dan ties sebanyak 1 artinya ada 1 responden yang tidak berubah kekuatan ototnya setelah diberikan mirror therapy dan didapatkan $p$ value 0,000 lebih kecil dari $\alpha=0,005$ yang artinya ada pengaruh yang signifikan pemberian mirror therapy terhadap kekuatan otot pasien stroke non hemoragik dengan hemiparese.

Tabel 4 menunjukkan bahwa jumlah negative ranks 0 artinya tidak ada responden yang status fungsionalnya berkurang setelah diberikan mirror therapy, positif ranks 15 artinya ada 15 responden mengalami perubahan status fungsional setelah diberikan mirror teraphy dan ties 1 artinya ada 1 responden yang tidak mengalami perubahan status fungsional setelah diberi latihan mirror therapy dan didapatkan nilai $p$-value 0,001 lebih kecil dari $\alpha=0,005$ yang artinya ada pengaruh signifikan pemberian mirror therapy terhadap status fungsional pasien stroke non hemoragik dengan hemiparese. 
Tabel. 1. Distribusi karakteristik responden stroke non hemoragik

\begin{tabular}{|c|c|c|c|}
\hline Variabel & & Frekuensi & Presentase (\%) \\
\hline \multicolumn{4}{|l|}{ Usia } \\
\hline a. Minimum & 48 & & \\
\hline b.Maksimum & 68 & & \\
\hline c. Mean & 55,75 & & \\
\hline d. Median & 55,5 & & \\
\hline e. Standar Deviasi & 5,98 & & \\
\hline \multicolumn{4}{|l|}{ Jenis Kelamin } \\
\hline a. Laki-laki & & 9 & 56,25 \\
\hline b. Perempuan & & 7 & 43,75 \\
\hline \multicolumn{4}{|l|}{ Frekuensi Stroke } \\
\hline a. Serangan $1 \mathrm{x}$ & & 12 & 75 \\
\hline b. Serangan $>1 \mathrm{x}$ & & 4 & 25 \\
\hline \multicolumn{4}{|l|}{ Riwayat Hipertensi } \\
\hline a. Ya & & 16 & 100 \\
\hline b. Tidak & & 0 & 0 \\
\hline Total & & 16 & 100 \\
\hline
\end{tabular}

Tabel 2. Analisis perbedaan Kekuatan Otot dan Status Fungsional Responden stroke non hemoragik sebelum dan setelah dilakukan intervensi mirror teraphy pada pasien stroke non hemoragik

\begin{tabular}{lccccc}
\hline Variabel & Mean & Median & Std.Deviasi & Minimum & Maximum \\
\hline Kekuatan otot & & & & & \\
a. Pre Intervensi & 2,69 & 3.00 & 0,48 & 2 & 3 \\
b. Post Intervensi & 3,63 & 4 & 0,62 & 2 & 4 \\
Status Fungsional & & & & & \\
a. Pre Intervensi & 42,5 & 50 & 18,71 & 10 & 65 \\
b. Post Intervensi & 72,5 & 80 & 21,45 & 10 & 95 \\
\hline
\end{tabular}

Tabel 3. Hasil Analisa Pengaruh mirror therapy terhadap kekuatan otot pada pasien stroke non hemoragik

\begin{tabular}{llcccc}
\hline & \multicolumn{5}{c}{ Ranks } \\
\hline \multirow{3}{*}{ Pretest-Postest } & $\mathrm{N}$ & Mean Ranks & Sum of Ranks & $p$ value \\
& Negatif Ranks & 0 & 0 & 0 & 0.000 \\
& & & & & \\
& Positif Ranks & 15 & 8 & 120 & \\
& Ties & 1 & & & \\
\hline
\end{tabular}

Tabel 4. Hasil Analisa Pengaruh mirror therapy terhadap status fungsional pada pasien stroke non hemoragik

\begin{tabular}{llcccc}
\hline \multicolumn{5}{c}{ Ranks } & \\
\hline \multirow{5}{*}{ Pretest-Postest } & N & Mean Ranks & Sum of Ranks & $p$ value \\
& Negatif Ranks & 0 & 0 & 0 & 0.001 \\
& & & & & \\
& Positif Ranks & 15 & 8 & 120 & \\
& Ties & 1 & & & \\
\hline
\end{tabular}




\section{PEMBAHASAN}

Hasil kekuatan otot dan status fungsional responden setelah dilakukan intervensi mirror teraphy mengalami peningkatan. Stroke menyebabkan aliran darah ke otak terganggu sehingga terjadi iskemia yang berakibat kurangnya aliran glukosa, oksigen dan bahan makanan lainnya ke sel otak. Gejala klinis setiap individu berbeda tergantung daerah otak mana yang mengalami kekurangan suplai darah, Murtaqib (2012). Kelemahan anggota gerak pada stroke merupakan gejala yang umum di jumpai, kelemahan yang ditemukan berupa kelemahan pada sisi kanan atau kiri. Gangguan pada arteri serebri media menyebabkan hemiparesis kontralateral yang lebih dulu mengenai lengan. Penyumbatan tersebut sering menyebabkan kelemahan otot dan spastisitas kontrolateral serta defisit sensoris. Hemiparesis akan terjadi akibat lesi vaskuler daerah batang otak seisi yang memperlihatkan ciri alterans yaitu pada lesi hemiparesis ipsilateral, sedangkan lesi hemiparesis distal bersifat kontrolateral. Paralisis (kelumpuhan) merupakan gejala klinis yang ditimbulkan oleh penyakit stroke (Murtaqib, 2015).

Kejadian stroke dapat menimbulkan kecacatan bagi penderita yang mampu bertahan hidup akibat berkurangnya kekuatan otot. Defisit kemampuan jangka panjang yang paling umum terjadi karena stroke adalah hemiparese yang akhirnya menyebabkan pasien mengalami komplikasi. Komplikasi tersebut tidak hanya membatasi pasien untuk mandiri dalam melakukan Activity Daily Lives
(ADL), namun juga meningkatkan ketergantungan pasien pada keluarga dan memiliki dampak ekonomi terhadap pasien, keluarga dan masyarakat (Esa, 2007).

Hasil Penelitian ini sejalan dengan Aini (2013) dimana rata-rata responden memiliki kekuatan otot 3 sebanyak 25 orang responden, sedangkan hasil penelitian Sherly, et al (2014) didapatkan sebanyak 15 orang $(50 \%)$ responden status fungsional sebelum dilakukan latihan adalah kategori ketidakmampuan parah. Hasil penelitian lain oleh Fadli (2017) menunjukan status fungsional pasien stroke sebelum dilakukan tindakan sebanyak 5 orang (21\%) respoonden kategori ketergantungan sedang dari total 18 responden.

Kejadian stroke merubah kemampuan seseorang akibat dari berkurangnya kekuatan otot yang berdampak pada rendahnya kategori kemampuan status fungsional. Kekuatan otot danStatus fungsional ini sendiri diukur dengan menggunakan skala kekuatan otot dan lembar observasi barthel index. Skala pada barthel index menggambarkan 10 kegiatan yang merupakan kegiatan rutin sehari-hari yang dinilai dari waktu yang dibutuhkan untuk melakukan dan besarnya bantuan yang diperoleh oleh pasien. Sejumlah 10 kegiatan yang dijadikan sebagai dasar skala pengukuran memiliki nilai dengan rentang 0 hingga 100 dan disimpulkan dalam 5 kategori yakni ketergantungan penuh, berat, sedang, ringan, dan mandiri. Ketergantungan penuh merupakan kategori dengan tingkat terparah dan mandiri merupakan kategori yang paling baik (Quinn, et al., 2011). 
Hasil pengamatan setelah dilakukan intervensi latihan mirror teraphy sebanyak 2 kali dalam sehari dan dilakukan selama 7 hari menunjukkan bahwa terdapat peningkatan setelah diberikan latihan mirror theraphy pada ekstrimitas atas dan ekstrimitas bawah. Perubahan status fungsional setelah diberikan intervensi mengalami perubahan yang positif dari rata-rata sebelum da setelah diberikan intervensi mirror therapy, kategori status fungsional didominasi oleh kategori ketergantungan sedang $62,50 \%$. Hasil pengamatan ini jika dilihat secara keseluruhan terdapat pengaruh yang positif dari masingmasing kategori. Ketergantungan total dari $18,75 \%$ menjadi $6,25 \%$, ketergantungan berat dari $75,0 \%$ menjadi $18,75 \%$, dan belum ditemukan adanya responden yang langsung memiliki kemandirian dalam status fungsional mengingat intervensi yang diberikan hanya satu minggu.

Berdasarkan hasil observasi yang dilakukan oleh peneliti, didapatkan ada satu pasien yang tidak mengalami perubahan pada kekuatan otot dan status fungsionalnya setelah diberikan intervensi, pasien mengatakan saat latihan dilakukan pasien mengeluh nyeri pada anggota tubuhnya dan malas untuk menggerakkan badannya, pasien lebih memilih diam dan tidur di tempat tidur, selama latihan pasien juga tidak mau mengikuti instruksi latihan yang diajarkan oleh peneliti dengan benar, hal ini menunjukkan bahwa latihan yang rutin dan kesungguhan selama latihan sangatlah penting dalam membantu proses pemulihan stroke.

Hasil uji Willcoxon

menunjukkan nilai $p$ value 0,000 lebih kecil dari $\alpha=0,005$. Hasil penelitian ini sejalan dengan penelitian yang dilakukan oleh Meidian (2013) dimana rata-rata kekuatan otot meningkat antara sebelum intervensi $(2,93)$ dan sesudah intervensi (4,2). Hasil penelitian tentang status fungsional yang dilakukan oleh Fandri, et al (2014) didapatkan 5 orang yang mengalami peningkatan status fungsional dimana 2 orang pasien stroke yang memiliki status fungsional kategori sangat parah menjadi status fungsional kategori parah, dan 2 orang pasien stroke yang memiliki status fungsional kategori ketidakmampuan menengah menjadi status fungsional kategori ketidakmampuan ringan.

Menurut Setiyawan (2014), terapi cermin adalah intervensi terapi alternatif yang berfokus pada menggerakkan anggota tubuh yang tidak terpengaruh untuk menyampaikan rangsangan visual ke otak melalui pengamatan gerakangerakan tersebut di cermin. Pengamatan ini dapat merekrut korteks premotor untuk rehabilitasi motorik dari bagian otak yang terkena. Latihan gerakan ini juga merupakan sebuah upaya bagi para penderita stroke untuk mencapai keseimbangan status fungsional dan kemandirian pasien. Latihan ini berangsur-angsur akan memfungsikan kembali tungkai dan lengan pasien hingga memberikan kekuatan pada pasien tersebut untuk mengontrol hidupnya atau mampu melakukan aktivitas kehidupan sehari-hari (Evy et al, 2017).

Mirror therapy dapat bermanfaat pada pasein untuk meningkatkan kekuatan otot pasien dan mencegah komplikasi dari perawatan pasca stroke pada pasien 
dengan syarat jika dilaksanakan sesuai jadwal minimal seminggu tiga kali dan sesuai dengan standar operasional prosedur yang ada. Terapi dengan menggunakan bantuan cermin ini juga dinilai mudah untuk dilakukan dan tidak membenani pasien. Terapi ini digunakan untuk melibatkan sistem mirror neuron pada korteks serebri untuk penyembuhan motorik tangan dan gerakan mulur (Evy et al, 2017).

Beberapa hasil penelitian tersebut menunjukkan bahwa mirror therapy ini merupakan terapi yang tepat sebagai program rehabilitasi pada pasien stroke yang membutuhkan perawatan yang lama dan intervensi ini terbukti efektif meningkatkan status fungsional motorik pasien stroke yang mengalami hemiparesis (Setiyawan,dkk 2019).

\section{SIMPULAN}

Kekuatan otot dan status fungsional pasien stroke setelah dilakukan intervensi mirror therapy mengalami peningkatan. Status fungsional pasien stroke setelah diberikan intervensi mirror therapy dapat menurukan tingkat ketergantungan pasien dimana sebelum diberikan intervensi, pasien memiliki ketergantungan berat dan setelah diberikan intervensi pasien memiliki tingkat ketergantungan sedang. Dengan demikian maka ada pengaruh yang signifikan intervensi mirror therapy terhadap kekuatan otot.

\section{SARAN}

Bagi praktisi kesehatan mirror therapy dapat digunakan sebagai penatalaksanaan dan perawatan untuk meningkatkan kekuatan otot dan status fungsional pasien stroke sehingga dapat meningkatkan kualitas asuhan keperawatan.

\section{DAFTAR PUSTAKA}

Agusman, Fery \& Kusgiarti Evy (2017). Pengaruh mirror therapy terhadap kekuatan otot pasien stroke hemoragik. Vol.4. No.3.

Andarwati \& Nur Aini (2013). Pengaruh latihan ROM terhadap peningkatan kekuatan otot pasien hemiparese post stroke di RSUD dr. Moewardi Surakarta. Skripsi Sarjana Ilmu Keperawatan Universitas Muhammadiyah Surakarta.

Adam, Muhammad et al (2014). Akupresur untuk meningkatkan kekuatan otot dan rentang gerak ekstremitas atas pada pasien stroke. Jurnal Keperawatan Indonesia. Vol.17. No. 3. Hal. 81-87.

Ary, Donald, Lucy C.J., \& Chris Sorenson (2011). Introducing to research in education eighth editoin. Canada : Nelson Edcation Wadsworth Cengange Learning.

American Heart Association (AHA) (2015). Heart Disease and Stroke StatisticsAtGlance(Artikel)http://www.h eart.org/idc/groups/ahamahpu blic/@wcm/@sop/@smd/docu mets/downloadable/ucm_4707 04.pdf.

Badan Penelitian dan Pengembangan Kesehatan RI (2013). Riset kesehatan dasar 2013. http://www.litbang.depkes.go.i d.

Dinarti, Elisa Ling et al (2015). Pengaruh range of motion (rom) pasif terhadap peningkatan sudut rentang 
gerak ekstrimitas atas pasien stroke di RSUD Tugurejo Semarang. Vol. 1 No. 1 (1-8).

Fandri, Sherly et al (2014). Perbedaan status fungsional pasien stroke saat masuk dan keluar ruangan rawat inap RSUD Arifin Achmad. Jurnal Online Mahasiswa Program Studi Ilmu Keperawatan Universitas Riau Vol.1. No. 2 (1-8).

Fitriyani, Wahyu Nur. (2015). Efektifitas frekuensi pemberian range of motion (rom) terhadap kekuatan otot pada pasien stroke di Instalasi Rawat Inap Rsud Prof. Dr. Margono Soekarjo Purwokerto. Universitas Muhammadiyah Purwokerto.

Hardiyanti, Lulus (2013). Pengaruh mirror therapy dibandingkan sham therapy terhadap perbaikan fungsi tangan : studi intervansi pada pasien stroke fase pemulihan. Fakultas Kedokteran Universitas Indonesia. Vol 4 No 1, 64-71

Jayanti, Alfica Agus. 2013. Hubungan hipertensi dengan kejadian stroke. Skripsi Program Studi Kesehatan Masyarakat Fakultas Kedokteran dan Ilmu Kesehatan Universitas Islam Negeri Syarif Hidayatullah Jakarta.

Khairunnisa, Neny. Fitriyani. 2014. Hemiparese sinistra, parese nervus VII, IX, XII e.c stroke non-hemoragik. Fakultas Kedokteran Universitas Lampung. Vol. 2. No. 3 (5259).

Karunia, Esa. 2007. Hubungan antara dukungan keluarga dengan kemandirian activity of daily living pasca stroke. Jurnal FKM_UNAIR Vol.4. (213224).

Meidian (2013). Pelatihan mirror neuron system sama dengan pelatihan constraint induced movement therapy dalam meningkatkan kemampuan fungsional anggota gerak atas pasien stroke. Jurnal Fisioterapi. Vol. 13. No. 2 (95108).

Murtaqib, M. (2015). Pengaruh latihan range of motion (ROM) aktif terhadap perubahan rentang gerak sendi pada penderita stroke di kecamatan tanggul kabupaten jember. Ikesma, 9(2). Retrieved From Https://Jurnal.Unej.Ac.Id/Inde x.Php/Ikesma/Article/View/16 70

Olivia, Ghea Rizki (2017). Pengaruh latihan mirror therapy terhadap kekuatan otot pada pasien stroke dengan hemiparese di Wilayah Kerja Puskesmas Kota Banjarmasin. Universitas Muhammadyah Banjarmasin.

Pratiwi, Anggi. (2017). Seminar dan workshop nasional keperawatan "implikasi perawatan paliatif pada bidang kesehatan. Progran Studi Ilmu Keperawatan Ners. STIK Bima Husada Palembang.

Prasadhana, et al (2016). pengaruh ROM pasif terhadap perubahan sudut sendi siku pada pasien stroke non hemoragik di RSUD dr.H.Soewondo Kendal. S.1 Ilmu Keperawatan STIKES Telogorejo Semarang.

Profil Kesehatan-Dinas Kesehatan Provinsi NTB. 2015. https://dinkes.ntbprov.go.id.

Rahayu, et al (2015). Pengaruh pemberian latihan range of 
motion (rom) terhadap kemampuan motorik pada pasien post stroke Di RSUD Gambiran. Vol.1. No.1.(102107).

http://ejournal.umm.ac.id/index .php/keperawatan/article/view/ 2864/3516

Rachmawati, Fitri et al (2013). Gambaran status fungsional pasien stroke saat masuk ruang rawat inap RSUD Arifin Achmad Pekanbaru. Vol.1. No.1 (1-9).

Rosiana, P.W (2009). Rehabilitasi stroke pada pelayanan kesehatan primer. Jakarta : Majalah Kedokteran Indonesia. Vol. 59. No. 2.

Smeltzer, Bare (2012). Keperawatan medikal bedah brunner and suddarth. Vol.2. EGC : Jakarta.

Sefulloh,M. Wayunah (2016). Analisis faktor yang berhubungan dengan kejadian stroke di rsud indramayu. Jurnal Keperawatan Indonesia. Vol.2 No.2 (65-76).

Setiyawan, et al (2019). Pengaruh mirror therapy terhadap kekuatan otot ekstrimitas atas pada pasien stroke di RSUD dr.MOEWARDI. Vol. 7. No. 1.

Trisnowiyanto, Bambang (2012). Intervensi pemeriksaan fisioterapi dan penelitian kesehatan. Nuha Medika. Yogyakarta.

Udayani, Giri. (2013). Faktor resiko kejadian stroke. Jurnal Kesehatan Metro Sri Wawai. Vol.1 No.1 (49 - 57).

Wiyantara, I Gede Arsana (2014). Pengetahuan keluarga tentang latihan rentang gerak (rom) pada pasien stroke di Ruang Rawat Inap RSU Provinsi Nusa Tenggara Barat. Politekknik Kesehatan Mataram Jurusan DIII Keperawatan.

Yudha, Fajar (2014). Pengaruh range of motion (ROM) terhadap kekuatan otot dan rentang gerak pasien pasca perawatan stroke. Lampung.

Yulinda, Wina (2009). Pengaruh empat minggu latihan pada kemampuan motorik penderita stroke iskemia di rsup h.adam malik. Medan 